adhesion with which to work. The relationship we established preserves an independent and strong Isis and merges the strengths of the two companies' programs.

\section{Conclusion}

Basic concepts concerning disease are changing, and this in turn is changing the way that drug discovery is undertaken. Our changing concept of disease, based on mechanisms and targets rather than signs and symptoms, will eventually alter all elements of the pharmaceutical industry. This new paradigm has created a need for higher fidelity drug interactions. The exploration of new drug discovery platforms, while optimally exploiting traditional drug discovery methods and responding to day-to-day commercial challenges, will require organizational flexibility that can best be achieved via synergies between biotechnology and major pharmaceutical companies.

\section{Acknowledgments}

I am pleased to acknowledge the assistance of Colleen Matzinger in the preparation of this manuscript. Thanks also to Dr. Jane Green for her thoughtful review.

\title{
Mycogen poised for the agbiotech range wars
}

Russ Hoyle

In past few months, the lines of battle in what promises to be a hotly contested agbiotech range war have been drawn. The hard-nosed cowboys among the biotechnology outfits-some battered and bleeding, others with still-gleaming spurs and bankrolls-are lining up multinational muscle in anticipation of the billion-dollar roundup in biopesticides, insecticides, and herbicides that is still a few years off,

The early skirmishes have already begun in earnest. The faceoff between Monsanto (St. Louis, MO), now allied with DeKalb Seeds (DeKalb, IL) and Calgene (Davis, CA), and Dow Chemical (Midland, MI) and Eli Lilly (Indianapolis, IN), in their new partnership with Mycogen (San Diego, CA), should be especially heated.

Among the most prominent of the cowboys who have seen their first products to the marketplace is Roger Salquist, CEO of Calgene. Salquist managed to save himself by selling off $49.9 \%$ of the company that is famous for the genetically modified Flavr Savr tomato to Monsanto. The deal reportedly gives Monsanto the rights to acquire $100 \%$ of Calgene by the year 2000 .

That may not be good news for Salquist. Whether or not he continues to play a leading role in running the company-an eventuality that eluded G. Kirk Raab in the Genentech-Roche deal-pales next to how well the alliance with Calgene works for Monsanto, the chemical giant that is intent on carving out a role for itself in the lucrative U.S. and international crop protection industry. Monsanto, however, must overcome potential jus tice department (Washington, D.C.) snags over potential unfair market dominance stemming from Calgene's ownership of the Stoneville Cotton Co., which makes a pestresistant Bacillus thuringiensis $(B t)$ gene for cotton seed, and Monsanto's own business, licensing the $B t$ trait in cotton seed to farmers.

If the deal clears government hurdles as expected, it will give Monsanto a dominant share in the developing marketplace for pestresistant and herbicide-resistant products. In late January, Monsanto's Ceregen subsidiary, whose business is the development of diseaseresistant, pest-resistant and herbicide-resistant crops, also announced that it had completed a \$25 million agreement to further bolster its pest-resistance business by acquiring a $14 \%$ stake in Ecogen (Langhorne, PA) along with the rights to its research into $B t$ technology for pest-resistant potato and cotton plants.

Besides Monsanto and DeKalb Seeds--yet another major corporate competitor on the receiving end of Monsanto's largesse-the latest and perhaps most interesting emerging corporate player is DowElanco (Midland, MI), a joint venture between the Dow Chemical Co and Eli Lilly. DowElanco's bid to play a major role in the drive to replace, or at least supplement, chemical pesticides, and herbicides with pesticide- and herbicide-resistant crops is interesting because it will be spearheaded by one of the canniest and level-headed executives in the biotechnology industry, Jerry Caulder, Mycogen's president and CEO.

Caulder has moved aggressively in recent months to beef up Mycogen's research, marketing, and financial clout, focusing on the company's specialties in insect-resistant and other enhanced seed products, as well as biopesticides, fungicides, and herbicides. Caulder, unlike some of his counterparts in the industry, has managed to make necessary acquisitions while maintaining control of his company.

Last year, Caulder started the ball rolling by acquiring an $80 \%$ interest in Agrigenetics Co. (Madison, WI), the seventh largest seed company in the U.S., and renaming the resulting entity Mycogen Plant Sciences. He also entered into a $\$ 51$ million research deal with Pioneer Hi-Bred (Des Moines, IA), which now controls $60 \%$ of the corn seed business, that would give Pioneer access to Mycogen's Bt patents for plant resistance.

Last month, Caulder put the finishing touches-for now, at least-on his acquisition strategy by closing a deal to buy United Agriseeds (Champaign, IL), the third largest U.S. corn seed company, from DowElanco, in exchange for 4.5 million shares of Mycogen common stock and $\$ 26.4$ million in cash. In a separate part of the complex deal, Caulder also picked off $\$ 8$ million worth of the rights to seed technologies for mid-oleaic corn, soybean, and sunflower oils from SVO Special Products (owned by Lubrizol), an early investor, and in Mycogen's seed business.

The deal was structured so that DowElanco ended up with $46 \%$ of Mycogen stock, in part through the sale of United Agriseeds, and in part by buying 9.5 million shares of Mycogen common stock from Lubrizol for $\$ 126$ million. Additionally, DowElanco received two positions on Mycogen's six-member board of directors and an agreement that will enable the Dow-Lilly venture to purchase additional Mycogen shares, although the terms of the accord were being kept under tight wraps.

The result is a company that should sell more than $\$ 100$ million worth of proprietary, genetically engineered seed products in 1996, based on its first year marketing a full range of products last year. How much did Caulder give away to carve out what he calls a "cornerstone" of Mycogen's business? The answer probably lies in Caulder's ability in the next two or three years to merge the new elements smoothly into Mycogen's corporate culture, continue the pace of marketing its core products and to produce new product lines. Among the latter: a $B t$ gene resistant to the corn rootworm borer (which DeKalb is also hard at work on), as well as developing $B t$ resistance beyond corn to canola, soybean, and sunflower seed crops, the focus of the Pioneer research agreement.

If they are smart, DowElanco's representatives on Caulder's board will give him free rein to do what he does best. Still, both Dow and Lilly will no doubt keep a keen eye out for innovative, bioengineered Mycogen products that might change the face of the chemical pesticides industry. Caulder is reportedly determined to stay on top and run his own business. More power to him. But the rough riding has only begun. 